\title{
Conservative heavy metal total discharge schemes
}

\author{
Tzung-Yuh Yeh ${ }^{1} \cdot$ Ho-Chi Chen ${ }^{1}$
}

Received: 6 July 2016 / Accepted: 29 May 2017 / Published online: 23 August 2017

(C) Springer-Verlag Berlin Heidelberg 2017

\begin{abstract}
Currently, according to Taiwan's Water Pollution Control Act, the environmental control of waterbodies and water quality depends on the effluent standards and the standard of water quality in the rivers. The Act demands that each stationary pollution source comply with the effluent standard before being discharged into the rivers, and that the overall water quality in the river shall not exceed the declared standard of water quality. To improve the condition of the waterbodies and water quality of the rivers, the Environmental Protection Administration (EPA) in Taiwan has made stricter regulations concerning the discharge standard. Such regulations will help to reduce the weight of individual pollutants discharged; the discharged wastewater, however, will still gradually worsen the water quality of the rivers even after complying with the effluent standard since some of the pollutant dischargers may decrease the concentration of pollutants by diluting the water before discharging; thus, the total weight of metals discharged in the rivers will not be reduced, and the water quality in the areas where the pollutant sources are concentrated will not thereby be significantly improved. To protect the irrigation water and farmlands from being polluted by discharged heavy metals in industrial wastewater, the EPA started controlling the sources in accordance with the total quantity control (TQC) as defined in the Water Pollution Control Act, in the hope of perfecting the environmental protection of waterbodies and water quality, as well as
\end{abstract}

Responsible editor: Philippe Garrigues

Tzung-Yuh Yeh

tyyeh@nuk.edu.tw

1 Department of Civil and Environmental Engineering, National University of Kaohsiung, Kaohsiung 811, Taiwan ensuring clean water sources without any pollution for the rivers, land, and people.

Keywords EPA $\cdot$ TMDL $\cdot$ TQC

\section{Introduction}

To protect the irrigation water and farmlands from being polluted by discharged heavy metals in industrial wastewater, the EPA started controlling the sources in accordance with the total quantity control (TQC) as defined in the Water Pollution Control Act. In addition, the Administration also revised the "Guidelines for Management of the Preventive Measure Plan for Water Pollution and Permission Inspection" to not only assist local governments in establishing and declaring total pollutant weight control areas but also to restrict the issuing of permits to enterprises for discharging heavy metals in the control areas. If there is a severe violation against the regulations in the control areas, the permits of the violators will be withdrawn by the Administration, and the violators will be unable to subsequently obtain other types of permits from the Administration. Currently, the pollutants which need the TQC include $\mathrm{Cu}, \mathrm{Zn}, \mathrm{Ni}, \mathrm{Cd}, \mathrm{Cr}$, and $\mathrm{Cr} 6+$, which are the heavy metals in the discharged wastewater generated through the processes employed by various enterprises, such as plating, chemical engineering, dyeing, and paper manufacturing. The local governments will be in charge of the classification of restricted areas for total pollutant load control. The areas where the qualities of irrigated rivers or waterbodies are in non-compliance with the irrigation water quality standard will be classified as Level 1 Control Areas. In the areas declared as Level 1 Control Areas, the establishment of factories that will discharge the said six types of heavy metals will be prohibited; for those already established, the 
discharge standards will be stricter than the current "effluent discharge standards," with enforcement upgraded to the more rigorous "irrigation water standard." For example, the level of $\mathrm{Cd}$ discharge standard will be 3-fold stricter, $\mathrm{Cr}$ will be 20fold stricter, etc. The authorities will withdraw the licenses of violators and will not reissue them again. Although the government has legislated relevant acts to demand that manufacturers make sure that their discharged wastewater complies with the effluent standards, traces of heavy metals in the wastewater can still accumulate in the soil through agricultural irrigation after being discharged into the waterbodies. The accumulated heavy metals will be absorbed by crops from the soil, and then eaten by humans. As a result, the heavy metals will continue to accumulate in the human body and threaten people's health.

The EPA has taken three measures to control farmland pollution from the source. First, the Administration raised the levels of discharge standards for industrial wastewater. Second, the Administration strengthened the management concerning the granting of permission to discharge industrial wastewater. Third, the Administration strengthened its cooperation with local governments, which are in charge of establishing the TQC areas and declaring the TQC implementation plan. Currently, the governments of Taoyuan City, Taichung City, and Changhua County have accomplished the establishment of the TQC areas and the implementation plan. In addition, the Water Pollution Control Act authorizes local governments to restrict enterprises in order to control the total weight of discharged heavy metals in waterbodies. When the total weight of the heavy metals in a waterbody exceeds the maximum load, the local governments can stop issuing permits to enterprises which discharge heavy metals into the waterbody. In other words, the local governments have the right to prohibit the enterprises that may discharge heavy metals from building new factories in agricultural irrigation areas. If the enterprises are unable to comply with the stricter levels of effluent standard, they can choose whether to discharge wastewater into places outside the control areas or to set their factories within industrial areas, where the wastewater will be collected for further management. By so doing, the enterprises can survive, and the sources of irrigation water as well as the excellent farmlands can be protected.

\section{Facilitation of total discharge weight control areas for waterbodies in farmlands}

Reducing the weight of heavy metals discharged by factories

- Raise the level of discharge standards for heavy metals for enterprises and sewage sewer systems in the Control Areas
The maximum loads of $\mathrm{Cu}, \mathrm{Zn} 6+, \mathrm{Cr}, \mathrm{N}, \mathrm{Cd}$, and $\mathrm{Cr} 6+$ contained in the TQC areas will be defined respectively for newly established enterprises, already established enterprises, and sewage systems according to the levels of management.

In Level 1 TQC areas, the standard of effluents discharged by enterprises already established in the area shall be the same as the one for irrigation water as defined by the Council of Agriculture. In Level 2 TQC areas, the standard of effluents discharged by newly established enterprises shall be the same as the one for irrigation water as defined by the Council of Agriculture, and the one for enterprises already established in the areas shall be half of the values of the current effluent standard.

In industrial areas, the sewage sewer systems are not classified, and the standards of heavy metals, including $\mathrm{Cu}, \mathrm{Zn}$, $\mathrm{Cr}, \mathrm{Ni}, \mathrm{Cd}$, and $\mathrm{Cr} 6+$, are half of the values of the current pollutant effluent standards, as shown as Table 1. In Level 1 Control Areas, enterprises which generate the said six types of heavy metals are banned from being established, amended or added. The standard values of the control for those which are already established in the areas (with a 2-year grace period) are respectively as follows: $\mathrm{Cu}(0.2 \mathrm{mg} / \mathrm{L}), \mathrm{Zn}(2.0 \mathrm{mg} / \mathrm{L}), \mathrm{Cr}$ $(0.1 \mathrm{mg} / \mathrm{L}), \mathrm{Ni}(0.2 \mathrm{mg} / \mathrm{L}), \mathrm{Cd}(0.01 \mathrm{mg} / \mathrm{L})$, and $\mathrm{Cr} 6+$ $(0.025 \mathrm{mg} / \mathrm{L})$. In Level 2 Control Areas, the ones for those which are already established in the areas (with a 2-year grace period) are respectively as follows: $\mathrm{Cu}(1.5 \mathrm{mg} / \mathrm{L}), \mathrm{Zn}$ (2.5 mg/L), Cr (1.0 mg/L), Ni (0.5 mg/L), Cd (0.015 mg/L), and $\mathrm{Cr} 6+(0.25 \mathrm{mg} / \mathrm{L})$, whereas the ones for those which are newly established are respectively as follows: $\mathrm{Cu}(0.2 \mathrm{mg} / \mathrm{L})$, $\mathrm{Zn}(2.0 \mathrm{mg} / \mathrm{L}), \mathrm{Cr}(0.1 \mathrm{mg} / \mathrm{L}), \mathrm{Ni}(0.2 \mathrm{mg} / \mathrm{L}), \mathrm{Cd}(0.01 \mathrm{mg} / \mathrm{L})$, and $\mathrm{Cr} 6+(0.025 \mathrm{mg} / \mathrm{L})$. For the sewage sewer systems in industrial areas (with a 2-year grace period), the ones are respectively as follows: $\mathrm{Cu}(1.5 \mathrm{mg} / \mathrm{L}), \mathrm{Zn}(2.5 \mathrm{mg} /$ L), $\mathrm{Cr}(1.0 \mathrm{mg} / \mathrm{L}), \mathrm{Ni}(0.5 \mathrm{mg} / \mathrm{L}), \mathrm{Cd}(0.015 \mathrm{mg} / \mathrm{L})$, and $\mathrm{Cr} 6+(0.25 \mathrm{mg} / \mathrm{L})$. Furthermore, the ones for those established outside of the control areas are respectively as follows (the current standards): $\mathrm{Cu}(3.0 \mathrm{mg} / \mathrm{L}), \mathrm{Zn}$ $(5.0 \mathrm{mg} / \mathrm{L}), \mathrm{Cr}(2.0 \mathrm{mg} / \mathrm{L}), \mathrm{Ni}(1.0 \mathrm{mg} / \mathrm{L}), \mathrm{Cd}$ $(0.03 \mathrm{mg} / \mathrm{L})$, and $\mathrm{Cr} 6+(0.5 \mathrm{mg} / \mathrm{L})$. Finally, the ones for the irrigation water quality are respectively as follows: $\mathrm{Cu}(0.2 \mathrm{mg} / \mathrm{L}) \mathrm{Zn}(2.0 \mathrm{mg} / \mathrm{L}) \mathrm{Cr}(0.1 \mathrm{mg} / \mathrm{L}) \mathrm{NI}$ $(0.2 \mathrm{mg} / \mathrm{L})$, and $\mathrm{Cd}(0.01 \mathrm{mg} / \mathrm{L})$ (Table 1$)$.

- Press Enterprises to adopt the optimal technologies to enhance the efficacy of wastewater remediation.

- Strengthen the management of permission for industrial wastewater discharge.

- Establish or amend the standard limits for enterprises which will discharge heavy metals in the TQC areas.

- Raise the levels of management on permission to discharge industrial wastewater.

- Establish TQC areas

- Assist and monitor local governments in the establishment of TQC areas and the declaration of the TQC plan. 
Table 1 The current effluent standards in Taiwan and South Korea and the effluent heavy metals in Level 1 and 2 TQC areas defined by the draft plan

\begin{tabular}{|c|c|c|c|c|c|c|}
\hline Item & $\mathrm{Cd}$ & $\mathrm{Cr}$ & $\mathrm{Cr} 6+$ & $\mathrm{Cu}$ & $\mathrm{Zn}$ & $\mathrm{Ni}$ \\
\hline Current effluent standards in Taiwan & 0.03 & 2 & 0.5 & 3 & 5 & 1 \\
\hline Current effluent standards in South Korea & 0.1 & 2 & 0.5 & 3 & 5 & 3 \\
\hline Level 1 control areas in the draft plan (already established enterprises) & 0.01 & 0.1 & 0.025 & 0.2 & 2 & 0.2 \\
\hline Level 1 control areas in the draft plan (newly established enterprises) & \multicolumn{6}{|c|}{$\begin{array}{l}\text { The standards of total weight and the daily weights of discharged heavy metals } \\
\text { are not allowed to be added, amended, or raised. }\end{array}$} \\
\hline Level 2 control areas in the draft plan (already established enterprises) & 0.015 & 1 & 0.25 & 1.5 & 2.5 & 0.5 \\
\hline Level 2 control areas in the draft plan (newly established enterprises) & 0.01 & 0.1 & 0.025 & 0.2 & 2.0 & 0.2 \\
\hline Sewage sewer systems in industrial areas & 0.015 & 1 & 0.25 & 1.5 & 2.5 & 0.5 \\
\hline Enterprises out of control areas (current standards) & 0.03 & 2.0 & 0.5 & 3.0 & 5.0 & 1.0 \\
\hline Irrigation water quality standards & 0.01 & 0.1 & - & 0.2 & 2.0 & 0.2 \\
\hline
\end{tabular}

Unit $\mathrm{mg} / \mathrm{L}$

- represents no control standards

The local authorities shall examine their own areas and draft the total pollutant weight control plan for waterbodies which have a priority need for controlling the total weight of pollutants, and then demand that the EPA consult with the target industry's competent authorities for ratification of the plan before implementing. The content of the plan shall include the following items:

1. Environment background regarding the sewage catchment area near the waterbody:

The plan shall provide information regarding the environment within the sewage catchment areas near the waterbody, including hydrological data analysis, land uses, population distribution, industrial characteristics, trends of environment changes in the past decade, as well as forecasts of environment changes affected by relevant future developments.

2. Waterbody usages, water quality standards and assessment of water quality investigation:

The plan shall provide the analysis on the waterbody usages, water classification, and water quality standards for different usages, as well as information regarding the standards of the required water quality. The abovementioned documents shall include the monthly inspection records of water quality and water content for 5 years and above.

3. Investigation and analysis of pollutant source and weight

The plan shall investigate and analyze the influential factors of the target pollutants from the point sources, similar point sources and non-point sources (i.e., non-fixed places where rainwater enters the waterbodies) in each subcatchment area, including the produced weight, reduced weight, concentration load of plunge points, etc., and then draw illustrations to mark the relative positions. The produced weight, reduced weight, and concentration load of plunge points of the target pollutants in the respective sources of point source pollution shall include the daily average weights and daily maximum weights.

\section{Target pollutants and objectives of water quality improvement:}

The plan shall list the priority target pollutants. The objectives of water quality improvement shall be specific and numerical, and the target values for the water quality improvement shall be defined yearly for more than 5 years. Depending on the jurisdiction, characteristics, and drafted reduction measures of the waterbody, the plan may establish overall objectives and annual sub-objectives, respectively, for each specific area if necessary.

\section{Design flow and water quality simulation:}

The plan shall include the water quality simulation, which shall be adopted by domestic engineering practices or academic researchers, and have actual performances to prove its effectiveness after calibration and verification. The reason for the adoption of the water quality simulation as well as the statement of applicability for relevant simulation shall also be explained in detail. The design flow adopted in the simulation shall be based on the average daily flow of the waterbody to represent its character statistically

Assimilative capacity analysis:

By using water quality simulation, the plan analyzes the target pollutants, objectives of water quality improvement, and selected design flow. When the objectives of water quality improvement are achieved, an analysis of the total discharged weight of the allowable target pollutants shall be conducted. 
6. Total pollutant discharge allocation and margins of safety:

The total weight of pollutant discharge shall be allocated to the pollutant sources, depending on their weights of pollutant discharge, margins of safety, and required weights of pollutant discharge in accordance with future development. When conducting the allocation, the produced weight, reduced weight, and concentration ratio of the pollutants in each pollutant source shall be taken into account. The margins of safety and the required weights of pollutant discharge in accordance with future development shall be defined as 5 to $10 \%$ of the assimilative capacity.

7. Reduction of point source pollution and measures of discharge control management:

When the local authorities allocate the pollutant discharge weights to the point sources, they shall consider the needs of waterbody improvement, general legal doctrines and principles, technology, and economics, as well as administrative feasibility, and then invite relevant authorities and point sources to a conference for the establishment of the allocation principles. After the pollutant discharge weights are allocated to the point sources, the local authorities shall amend or ratify the individual permits (documents) for the point sources depending on their allocated discharge weights in accordance with Article 15, Section 2 of the Regulation Governing Implementation of Total Water Pollutant Weight Control, as well as Article 28, Section 2 of the Regulations Governing Water Pollution Control Measure Plans, and Permit Application Review. Nevertheless, the allowable quantity of pollutant discharge shall not be greater than the one complying with the effluent standards.

When the local authorities allocate the pollutant discharge weights to similar point sources, they will consider the needs of waterbody improvement, technology, and economics, as well as government finance. Meanwhile, the similar point sources will be invited to a consultation regarding the allocation; they can provide suggestions on specific and feasible measures of pollutant reduction according to the characteristics and allocated weights of the pollutant discharge from the similar point sources. The measures of pollutant reduction shall be conducted before being included in the waterbody where the TQC is implemented. For those who conduct management measures, the local authorities shall demand that they submit the relevant evidence within the term defined in the total pollutant weight control plan to prove the efficacy of their reduction measures for water quality improvement. As for those who conduct the engineering measures, the local authorities shall demand that they complete the engineering measures within the term defined in the total pollutant weight control plan and submit the report in which the content of engineering measures and the evidence related to water quality improvement are included.
8. Pollution reduction in non-point sources and feasible reduction measures:

When the local authorities allocate the pollutant discharge weights to the non-point sources, they shall identify the specific and feasible locations and measures to reduce pollutants according to the time and space distribution of the sources of the pollutant discharge, and then invite the relevant authorities to consult about the implementation of the allocation. The local authorities shall demand that the non-point sources submit the content and results of conducting the measures of water quality improvement within the term defined in the total pollutant weight control plan.

9. The terms of the reduction measures.

10. Water quality monitoring and effects assessment plan:

The water quality monitoring and effects plan shall be conducted by adding monitoring spots in the locations outside of the routine monitoring stations of the EPA. The sampling frequency shall be once per month except when special events occur. The items of the sampling shall include the target pollutants that may affect the water quality; the method of continuous automatic monitoring shall be adopted for the sampling. The terms of the monitoring shall cover both the high and low water periods of all the years defined in the total pollutant weight control plan. The implementation of the continuous automatic monitoring shall be taken by using mature techniques outside the limits of the methods declared by the Environmental Analysis Laboratory of the EPA.

11. Regulations drafted in accordance with the authorization granted under the Local Self-Government Regulations and Water Pollution Control Act.

The objects of the TQC are classified as follows:

1. Point sources: the enterprises which discharge wastewater (sewage) into the waterbody in the TQC areas, and the authorities (institutions) in charge of the management of sewage sewer systems

2. Similar point sources: storm sewers, roadside drainages or irrigation channels, and the authorities (institutions) in charge of the management of those who discharge water and target pollutants into waterbodies in the TQC areas

3. Non-point sources: the areas where the target pollutants run off into waterbodies from the banks due to rainfall erosion, and the authorities (institutions) in charge of the management of the land where the waterbodies are located

The cooperation request of the point sources, similar point sources, and non-point sources for the purpose of 
improvement of water quality in the TQC plan, including the prevention measures of water pollution, the prohibited actions or self-testing, and monitoring records, etc., shall be defined respectively and declared for implementation by establishing additional local self-government regulations in the TQC plan or in accordance with the authorization granted under the Water Pollution Control Act.

\section{Division of cooperation between central and local governments}

The objective cities, counties, and areas that need implementation, in priority are as follows:

- The cities and counties where the farmlands have been severely polluted for a long time

- The lands which are polluted for a second time after the precedent remediation

- The areas where the major enterprises are certainly defined as the pollutant sources for discharging wastewater

\section{Implementation strategies}

- The polluted farmlands and the areas with high potential to be polluted in Taoyuan, Changhua, and Taichung shall undertake the implementation in priority.

In accordance with Article 9 in the Water Pollution Control Act, the TQC planned by Taoyuan City Government focuses on the partial basin of Xinjie River and Puxin River that need particular care. The basin not only collects rain water and sewage but also wastewater discharged by the enterprises in Huangchyan River basin, tributary of Puxin River in the upstream basin; it has irrigated 950 ha of farmlands for a long time, thereby causing the farmlands' heavy metal pollution to worsen daily. Currently, the area of the control site for soil pollution has reached 145 ha. To keep the farmlands in excellent quality, the quality improvement of the source of irrigation water needs to be conducted urgently. Taoyuan City Government has included the basins of Xinjie River and Puxin River in the TQC areas and classified the levels for management. The waterbody in Huangchyan River basin has been classified as a Level 1 TQC area, since it is the tributary of Puxin River in the upstream basin. The waterbodies in the basins of Xinjie River and other parts of Puxin River have been classified as Level 2 TQC areas.

The Level 1 TQC areas are located around Zhongli District and Luzhu District in Taoyuan City; the Level 2 TQC areas cover partial areas of Bade District, Dayuan District, Dasi District, Zhongli District, Pingzhen District, Taoyuan District, Longtan District, and Luzhu District, with a total area of 10,000 ha. According to the classified levels of TQC areas defined by Taoyuan City Government, the Chungli Industrial Zone and the Advanced Semiconductor Engineering, Inc. belong to the category of "Sewage sewer systems in Industrial Areas," both located in the Level 1 TQC area. As for the Level 2 TQC areas, the objects are mostly PCB manufacturers. In the future, 27 companies will be in the TQC areas that are included as the objects which need stricter control standards.

The target pollutants defined by the TQC of Taoyuan City are $\mathrm{Cu}, \mathrm{Zn}, \mathrm{Ni}, \mathrm{Cr}, \mathrm{Cr} 6+$, and $\mathrm{Cd}$. According to the latest regulation of the EPA, enterprises which generate the said six heavy metals during their manufacturing processes and/ or which are contained in the wastewater (sewage) are not allowed to receive any new permission license, and the daily weight and total weight of the wastewater containing the heavy metals cannot be increased or amended. Violators whose permits are withdrawn, or whose permission is abolished, will no longer get re-approval; as for those who committed to improvement but failed after 5 years of conduction to make the quality of the waterbody comply with the standards of irrigation water, permission will not be reapproved any longer after it becomes invalid, depending on the severity. The enterprises located in the Level 1 and Level 2 TQC areas, which discharge wastewater into the particular waterbodies, shall conduct wastewater remediation to make the quality comply with the stricter effluent standards before discharging. Meanwhile, according to Article 31 in the Water Pollution Control Act, the TQC areas where the daily loads of discharging wastewater exceed $1000 \mathrm{t}$, or where a major pollutant source appears, shall be monitored by establishing a continuous automatic monitoring system to check the weight and quality of the effluent within the defined period. The local governments also need to know the status of wastewater discharged from pollutant sources very well at any time.

The government of Changhua County has established "Guidelines for Implementation on the Protection of Farmlands in Total Weight Reduction Control Areas Governing the Waterbody and Water Quality of Dong-xi2nd and 3rd ditches, Changhua County." The guidelines establish TQC areas for the waterbody and water quality of Dong-xi-2nd and 3rd ditches, covering 1350 ha of total area, including a total of 22 villages in Changhua City and Hemei Township, where the enterprises discharge wastewater containing 6 types of heavy metal: $\mathrm{Cd}, \mathrm{Cr}, \mathrm{Cr} 6+, \mathrm{Cu}, \mathrm{Zn}$, and $\mathrm{Ni}$. The TQC areas and the administration areas are presented respectively in Table 2 .

In order to maintain the quality of the waterbody environment in Changhua County, the EPA and Changhua County Government have been effectively controlling the pollutant discharge of point sources for years through continuous legislation and enhancement of inspection. Nevertheless, since the factories are located close to the rivers or drainage channels, the rivers and drainage channels in the county may still face 
Table 2 Administration areas of total weight reduction control for specific farmland protection of the waterbody and water quality of Dong-xi-2nd and 3rd ditches, Changhua County

\begin{tabular}{|c|c|c|c|}
\hline County & Township & Villages & $\begin{array}{l}\text { Level of } \\
\text { TQC area }\end{array}$ \\
\hline $\begin{array}{l}\text { Changhua } \\
\text { County }\end{array}$ & $\begin{array}{l}\text { Changhua } \\
\text { City }\end{array}$ & $\begin{array}{l}\text { Xiabu Village, Zhongzhuang } \\
\text { Village, Wuquan Village, } \\
\text { Guyi Village, Xishi Village, } \\
\text { Hediao Village, Zhongquan } \\
\text { Village, Ayi Village, Jianan } \\
\text { Village, Guosheng Village, } \\
\text { Fuxing Village, Yangming } \\
\text { Village, Xinxing Village, } \\
\text { Wanan Village, Fushan } \\
\text { Village, Longshan Village }\end{array}$ & $\begin{array}{c}\text { Level } 1 \\
\text { TQC } \\
\text { area }\end{array}$ \\
\hline $\begin{array}{l}\text { Hemei } \\
\text { Township }\end{array}$ & $\begin{array}{l}\text { Hedong Vi } \\
\text { Village, } \\
\text { Xinzhua } \\
\text { Village, }\end{array}$ & $\begin{array}{l}\text { lage, Lisheng } \\
\text { Zhaoan Village, } \\
\text { hg Village, Jiali } \\
\text { Tieshan Village }\end{array}$ & \\
\hline
\end{tabular}

the potential risk of being polluted by heavy metals and becoming the sources of irrigation water for the neighboring fields. Moreover, because of the huge demands for irrigation water, it is difficult to conduct separation of irrigation and discharge. Consequently, to ensure that the specifically protected waterbody and water quality for the farmlands are secure, it is necessary to conduct more effective control on the point sources whose discharges may influence the waterbody and water quality of the sources of irrigation water.

According to the data collected by the Soil and Groundwater Pollution Remediation Fund Management Board, EPA, there are 2371 control sites of farmlands in total where soil and groundwater pollution have been declared. Among the control sites, 1072 of them (about 253 ha) have completed remediation, and 1299 of them (about $218 \mathrm{ha}$ ) are still being monitored. In addition, among the control sites still being monitored, 1038 of them are close to Dong-xi-2nd and 3rd ditches, suggesting that half of the polluted farmlands in Changhua County are mostly located within the irrigation areas of Dong-xi-2nd and 3rd ditches, so the quality of the sources of irrigation water is still facing the potential risk of being polluted by heavy metals.

As people have expressed concern regarding the food safety issue in recent years, Changhua County Government regards Dong-xi-2nd and 3rd ditches as the specifically protected waterbody for the farmlands in the County, according to its respective acts, thereby including the ditches among the Level 1 TQC areas to protect the waterbody of farmlands from being polluted, to maintain food safety, as well as to conduct proper management of the basin. Complying with the relevant regulations amended and issued by the EPA, measures of the management have been taken by the local authorities, including raising the level of effluent standards, managing water pollution prevention and control permits and documents, establishing automatic water quality monitoring systems for effluent, etc. By pressing the already established enterprises and the sewage systems to improve the measures of water pollution prevention and control, the discharge of heavy metals is being effectively reduced.

In Taichung City, the TQC areas cover $9.6 \mathrm{~km}^{2}$ of the downstream basin of Zhancuoyuan Drainage, including Dali Industrial Park. Besides the Industrial Park, 69 factories will be affected. Currently, the government has held three consultation meetings to facilitate its TQC plan, and the procedures will be drafted according to relevant regulations before the estimated public announcement for implementation in 2016.

- Local governments shall establish and declare their TQC areas to conduct the total pollutant weight control regarding the heavy metals discharged into ground water.

- Central authorities shall complete the regulations of management concerning the permits of industrial wastewater (sewage) discharge in TQC areas, as well as raise the level of effluent standards.

\section{Quality protection project for irrigation water}

According to the water quality monitoring data provided by the Irrigation Associations, approximately 5\% of irrigation water is currently of poor quality, mostly because of the wastewater (sewage) discharged into public waterbodies, the wastewater (sewage) discharged indirectly into irrigation channels through roadside drainages, the wastewater (sewage) discharged directly into irrigation channels without obtaining permission from the authorities or managing institutions, and the wastewater (sewage) discharged into irrigation channels with the permission of the local Irrigation Association. In order to improve the irrigation water quality, various measures for the effective control of polluted water and water discharging into irrigation sewage systems shall be adopted.

The Council of Agriculture, Executive Yuan, has facilitated the Quality Protection Project for Irrigation Water to effectively prevent the target wastewater (sewage) from being discharged into irrigation channels directly or indirectly, so that irrigation channels can have lower risks of being polluted, and the safety of crops can be guaranteed. To implement the Project, a series of measures has been conducted, including the following:

1. Enhancing the management and maintenance of irrigation water quality: The specific measures include enforcing the monitoring and management of irrigation water quality, as well as establishing the measure of discharge control in stages and areas with the permission of local Irrigation Associations. 
2. Enhancing the mechanism of prevention against pollution: The specific measures include enforcing the management and control of water pollution sources in agricultural areas and enhancing the assistance in the improvement of industrial wastewater discharge.

3. Enhancing drainage management and accelerating the establishment of sewer systems: The specific measures include enforcing drainage management and accelerating the establishment of sewer systems. The details, implementation descriptions, and competent authorities of the measures governing the Quality Protection Project for Irrigation Water are presented in Table 3.

\section{Relevant laws}

Currently, the domestic laws define the TQC as the control of the total weight of discharged pollutants in a given area in order to ensure that the weight does not exceed the carrying capacity of the waterbody in the area, so that the waterbody can maintain its basic condition for sustaining living things. The TQC also manages and controls the pollution loads of individual factories and institutions. Thus, in the areas where the river has bigger carrying capacity, the allowable quantity of pollution loads can be larger. For institutions (for example, sewage disposal plants in industrial areas), it is feasible to achieve the standard level of effluent concentration as defined in the regulated waterbody classification; for areas with smaller carrying capacity, however, the concentration standard of the effluent shall be stricter so that the water quality of the river will not be affected. The current Water Pollution Control Act has included the TQC within the relevant articles, namely, "total quantity control" in Article 9, and "water body classifications and water quality standards" in Article 6. According to Article 9 in the Water Pollution Control Act, "For a water body, in whole or in part, in one of the following circumstances, the special municipality, county, or city authorities shall implement controls using total quantity control methods for the discharge of wastewater or sewage based on the carrying capacity of the water body."

1. Those circumstances in which the use of effluent standards still fails to meet water quality standards for said water body due to the density of enterprises or sewage systems.

2. Those circumstances in which the authorities determine that special protection is required:

The total quantity control methods in the foregoing paragraph shall be drafted by the special municipality, county, or city authorities and shall be approved by the central authorities after consultation with the relevant industry authorities; in those circumstances in which a water body, in whole or in part, involves two special municipality, county, or city authorities or involves a special zone administered by more than one central industry authority, the central authorities in consultation with the relevant industry authorities shall determine the total quantity control methods in the foregoing paragraph.

According to Article 6, "The central authorities shall delineate water zones and determine water body classifications and water quality standards based on the special characteristics and on-site conditions of water bodies." The abovementioned articles are the legal sources of the TQC conduction. The implementation of the TQC method will be conducted based on the "water body classifications and water quality standards" as defined in Article 6.

\section{Effluent standards}

The effluent standards were established and declared by the Environmental Protection Bureau, Department of Health, Executive Yuan (currently known as the EPA) in 1987. The purpose was to demand that enterprises and institutions generating wastewater establish wastewater treatment facilities to reduce the impact of pollution on the waterbody from wastewater discharge. Based on the concentration levels, the Standards stipulated the methods to control the pollutants generated by factories, mines, or enterprises indicated by central authorities and discharged through the sewer outfalls. After the establishment of the EPA, the implemented effluent standards were regulated, depending on the usages of the waterbodies. Amended and declared in 1997, the new effluent standards were even stricter in regard to the limitation of pollutants. For most of the enterprises, it is necessary to enhance the efficiency of wastewater treatment to comply with the effluent standards. As a matter of fact, managing the water pollution solely based on the pollutant concentration may lead to the following defects:

1. If an enterprise is unwilling to spend money on wastewater treatment facilities, it may add large amounts of water to dilute the effluent concentration when the concentration exceeds the discharging standards. According to the mass balance principle, while such wastewater will comply with the concentration standards when discharging, the total quantity of discharged pollutants will not actually be reduced.

2. The Standards do not take carrying capacity into consideration. Each river has different carrying capacity. In other words, each river has a different maximum load of total pollutant quantity. If the authorities control the effluents only by monitoring the concentration, in the areas with high enterprise density, or where the waterbodies of the 
Table 3 Strategies and specific implementation measures regarding quality protection project for irrigation water

\begin{tabular}{llll}
\hline Strategies & Measures & Implementation description & Competent authorities
\end{tabular}

I. Enhance the management and maintenance of irrigation water quality
1. Enhance the monitoring and management of irrigation water quality

2. Establish the measures of discharge control in stages and areas with the permission of local Irrigation Associations

II. Enhance the mechanism of prevention of pollution

1. Enhance the management and control of water pollution sources in agricultural areas
(1) The Irrigation Associations shall enhance the conduction of irrigation water quality monitoring and increase the frequency.

(2) The Irrigation Associations shall enhance the monitoring and management of the quality of the water discharged by entities having the permission of the local Irrigation Associations.

(3) The Irrigation Associations shall enhance the monitoring of the sediments and heavy metals in the irrigation channels in high pollution risk farmlands (farmlands where the soil pollution control or remediation is located, and the farmlands where the crops are detected as polluted).

(4) The Irrigation Association shall frequently monitor and clean the sediments of the waterbodies.

(5)The EPA shall coordinate with local authorities to assist the Irrigation Associations in cleaning the sediments. Regarding the detection of the sediments, the EPA shall include it in the "Sediment Management Project."

(1) The Irrigation Associations shall facilitate their establishment in stages and areas, depending on the potential risks of pollution.

(2) The Irrigation Associations may preserve the right of approval or rejection of discharging into irrigation channels in the areas.
(1) The Ministry of Economic Affairs and local authorities shall assist factories in improving the wastewater quality, conduct the management and correction of illegal discharges, and enhance the investigation of unregistered factories.

(2) The EPA shall press local governments to enhance the inspection of effluents in water pollution sources (including illegally discharged water), and enhance the inspection and control of water pollution sources in high pollution-risk farmlands (the farmlands where the soil pollution control or remediation is located and the farmlands where the crops are detected to be polluted).

(3) For the areas where the pollution loads are heavier, the EPA shall press local government to deliberate about adding the effluent standards or raising the level of the standards, as well as conducting the TQC regarding wastewater (sewage) discharge.

(4) For the areas where the pollution loads are heavier, the EPA shall press local government to establish a contact platform to enhance the control,
- Inspection Agency: the Association

- Execution Agency: Irrigation Associations

- Assistance Agencies: the Environmental Protection Administration, Executive Yuan (hereinafter referred to as "the EPA"), and the local authorities

- Inspection Agencies: target industry competent authorities (Ministry of Economic Affairs, etc.), the EPA, and the Association

- Execution Agencies: local authorities and Irrigation Associations 
Table 3 (continued)

\begin{tabular}{|c|c|c|c|}
\hline Strategies & Measures & Implementation description & Competent authorities \\
\hline & $\begin{array}{l}\text { 2. Enhance the assistance in the } \\
\text { improvement of industrial } \\
\text { wastewater discharge }\end{array}$ & $\begin{array}{l}\text { inspection, and contact service regarding } \\
\text { the local pollutant sources. } \\
\text { (5) The Irrigation Associations shall } \\
\text { enhance the monitoring of the quality of } \\
\text { water discharged by approved } \\
\text { dischargers and report to the authorities } \\
\text { once any abnormal status occurs. In } \\
\text { addition, the Associations shall assist } \\
\text { local governments in the inspection and } \\
\text { control of water pollution sources. } \\
\text { (1) The Ministry of Economic Affairs is } \\
\text { devoted to enhancing the relevant } \\
\text { assistance in the improvement measures } \\
\text { in order to assist enterprises in regard to } \\
\text { the discharge prohibition measures, } \\
\text { including discharge modification } \\
\text { projects, attached (buried) discharge } \\
\text { pipes, process improvement, water sav- } \\
\text { ing measures, wastewater treatment and } \\
\text { reduction, as well as heavy metal reduc- } \\
\text { tion. }\end{array}$ & \\
\hline $\begin{array}{l}\text { II. Enhance the } \\
\text { mechanism of } \\
\text { prevention against } \\
\text { pollution }\end{array}$ & $\begin{array}{l}\text { 3. Enhance the assistance in the } \\
\text { improvement of industrial } \\
\text { wastewater discharge }\end{array}$ & $\begin{array}{l}\text { (2) The cities and counties where the } \\
\text { number of industrial dischargers is } \\
\text { greater, namely, Taichung City, } \\
\text { Kaohsiung City, Changhua County, } \\
\text { Taoyuan County, Yunlin County, and } \\
\text { Hsinchu County shall establish task force } \\
\text { platforms to integrate relevant resources } \\
\text { to implement the measures. } \\
\text { (3) The Irrigation Associations shall } \\
\text { provide canal lands for the establishment } \\
\text { of discharge pipes for wastewater. }\end{array}$ & $\begin{array}{l}\text { - Inspection Agencies: target industry } \\
\text { competent authorities (Ministry of } \\
\text { Economic Affairs, etc.), the EPA, and the } \\
\text { Association } \\
\text { - Execution Agencies: local authorities and } \\
\text { Irrigation Associations }\end{array}$ \\
\hline \multirow[t]{2}{*}{$\begin{array}{l}\text { III. Enhance drainage } \\
\text { management and } \\
\text { accelerate the } \\
\text { establishment of } \\
\text { sewer systems }\end{array}$} & 1. Enhance drainage management & $\begin{array}{l}\text { The Water Resources Agency, Ministry of } \\
\text { Economic Affairs, shall press the local } \\
\text { water administrations to enhance the } \\
\text { management of wastewater (sewage) } \\
\text { discharge and drainage. }\end{array}$ & $\begin{array}{l}\text { - Inspection Agencies: Water Resources } \\
\text { Agency (Ministry of Economic Affairs), } \\
\text { Construction and Planning Agency } \\
\text { (Ministry of the Interior), as well as } \\
\text { target industry competent authorities } \\
\text { - Execution Agency: local authorities }\end{array}$ \\
\hline & $\begin{array}{l}\text { 2. Accelerate the establishment of } \\
\text { sewer systems }\end{array}$ & $\begin{array}{l}\text { The Construction and Planning Agency, } \\
\text { Ministry of the Interior, the Water } \\
\text { Resources Agency, Ministry of } \\
\text { Economic Affairs, and local } \\
\text { governments shall continuously enhance } \\
\text { the construction of relevant drainage } \\
\text { systems, including regional drainage, } \\
\text { urban drainage, industrial drainage and } \\
\text { sewage systems. }\end{array}$ & \\
\hline
\end{tabular}

rivers have smaller carrying capacities, the water quality will worsen because the total discharged pollutant quantity may exceed the carrying capacity of the waterbodies. On the other hand, in areas where the rivers have larger carrying capacities, the maximum loads for discharged pollutants can also be larger, but the enterprises will still have the increased expense of wastewater treatment since the concentration standards remain the same. Monitoring only the concentration to control the effluent fails to properly apply the various carrying capacities of different rivers and will burden the enterprises with the expense of wastewater treatment facilities.

The term "carrying capacity" is defined in the Water Pollution Control Act as "the quantity of pollutants a waterbody can assimilate without jeopardizing its normal uses," and is related to a river's self-purification. When wastewater and sewage are discharged into rivers, the microorganisms will degrade the organic material to $\mathrm{CO}_{2}$ and $\mathrm{NO}_{3}$ by consuming the dissolved oxygen in the water. If the pollutant 
concentration is low, the consumed dissolved oxygen in the rivers can be replenished through the aeration of the water surface and photosynthesis of algae, so that the rivers can maintain their normal uses. This process is called river selfpurification. Nevertheless, if the pollutant concentration is too high, the dissolved oxygen will be decreased and initiate the process of anaerobic digestion; thus, the water quality in the rivers will be under anaerobic condition and lose their capacity for self-purification. Consequently, the carrying capacity in rivers really determines the total quantity of discharged pollutants.

\section{Economic incentives}

Among all the measures of economic incentives, collecting water pollution control fees is the most effective way to reduce pollutions, besides charging fines, and has brought successful results in many European countries. Collecting water pollution control fees can not only press the enterprises to enhance their wastewater treatment capacities but also to reduce the quantity of discharged pollutants and improve the current status of water pollution. By so doing, the development of environmentally friendly enterprises can be facilitated, and economic growth can be stimulated. In Taiwan, the implementation of charging water pollution control fees is clearly defined in the Water Pollution Control Act; the authorities shall collect water pollution control fees from entities which discharge wastewater or sewage into surface water bodies, based on their discharge water quality and water weight for national water pollution control matters. In addition, the fee collection rate offers sufficient incentives, thereby making the collection meaningful. Since the purpose of the collection is to facilitate the improvement of pollution sources, and the establishment and operation of wastewater treatment facilities, as well as to decrease pollutant discharge, the collection will lose its economic incentive if the rate is relatively lower than the wastewater treatment expense. Once the collection loses its economic incentive, it will become merely symbolic and unable to help improve the water quality.

Taking the origin and current status of total maximum daily load (TMDL) in California, the USA, as reference, the development of the TMDL in the USA was originally initiated according to the Clean Water Act (CWA) established by the US Environmental Protection Agency (USEPA). Under Section 303(d) of the Clean Water Act, states, territories, and authorized tribes (included in the term State here) are required to submit lists of impaired waters. All the waterbodies listed in the charts in Section 303(d) shall be controlled by monitoring the pollutant sources with the TMDL method in order to improve the water quality. Under the requirement of CWA, the USEPA demanded that every state government establish and develop the TMDL plan. Consequently, the California Environmental
Protection Agency (CalEPA) handed over the responsibility to the California State Water Resource Control Board and its nine subsidiary Regional Water Quality Control Boards.

In 2001, California established its first TMDL plan in California and drafted others afterwards according to the various natures of pollutants and basins.

By conducting the TMDL of pollutants in rivers, a sustainable water quality management resulted which does not exceed the environmental carrying capacity and complies with the principle of generational equity in order to fulfill the demands of socioeconomic development. The purpose of the TMDL plan governing river pollutants is to set the daily maximum loads and monitor the daily discharged pollutants under the defined prospects of waterbody usages and affordable risks, so that the rivers comply with the water quality standard. If a pollutant discharger cannot manage to reduce the pollutants to the allowable quantity, or even plans to increase the quantity due to the expansion stemming from economic development, it can trade with other dischargers through the effluent trading mechanism.

In the USA, a TMDL plan can be included in a Basin Plan, in which the implementation of pollutant source reduction will be clearly defined in order to achieve the ultimate goal of realizing a water pollution solution. The TMDL plans vary from a long- to a short-term basis. The terms can continue for years or decades, depending on the nature of the pollution, complications of the plan, and characteristics of the target waterbody. The procedures and descriptions of establishing a TMDL plan are as follows:

According to the USEPA's definition: "A TMDL is the calculation of the maximum amount of a pollutant allowed to enter a waterbody so that the waterbody will meet and continue to meet water quality standards for that particular pollutant. A TMDL determines a pollutant reduction target and allocates necessary load reductions to the point sources and non-point sources of the pollutant." The TMDL system includes the following process. First, the authorities will assess the water quality and provide technical analysis regarding the methods of pollution reduction and waterbody protection. Then, they will decide on the appropriate improvement measures or control methods and allocate various pollutant quantities in an economical and effective manner. Finally, the central authorities will certify the permits and continuously monitor the system to ensure its integrity.

- WLA: pollutant allocation for point sources (including similar point sources)

According to the USEPA's cases of TMDL implementation, the point sources that discharge pollutants include two major sites. The first one is the factories approved by the 
Federal or State governments, and the second is the Municipal Separate Storm Sewer System (MS4) approved by the Federal or State governments. Both of these shall acquire approval from the Federal or State governments before the discharge operation; thus, their points of discharge are clearly defined, and the content of discharged pollutants entering the target waterbodies and the result of the assessment are specifically registered in the records.

\section{- LA: pollutant allocation for non-point sources}

Non-point source pollution occurs after a rainfall. Some residual rainwater without infiltration, depression storage, and interception enters waterbodies together with the pollutants on the soil surface after forming runoff and pollutes the waterbodies. Since the place where such rainwater enters the waterbodies is not fixed, this kind of pollution is called nonpoint source pollution. Generally, because the time and space distributions of non-point source pollution are more complicated and unstable compared with point source pollution, it is difficult to manage the quantity of pollutants and the quality of the water. Consequently, compared with collection for treatment, source prevention through the Best Management Practices (BMPs) is regarded as the most feasible, cost-effective, and operative method globally. Among the cases of TMDL implementation in the USA, non-point source pollution has been assessed after collecting data on the status of land uses, hydrographic conditions, and the amount of rainfall. The subjects of the assessment are those excluded from urban development areas, including forests, farms, crop fields, pastures, non-centralized processing farms, and pollution from atmospheric deposition.

\section{- MOS: margins of safety}

An MOS is a conservative estimate which is similar to a safety factor and is defined after allocation and quantification, with consideration of the uncertainties of pollutant reduction in waterbodies when conducting pollutant allocation. Uncertain factors usually exist in the process of pollutant calculation or model stimulation. They occur in hypothetical conditions focusing on the realities and incur some slight limitations, for example, the background data cannot be fully collected or analyzed or the model and the actual condition are not properly matched (such as the hypothetical numbers or locations of entering points of the tributaries and drainages are not matched). Such limitations may lead to inaccurate calculations of pollutant quantity. Consequently, the MOS will be included in the implementation to represent the uncertainty and incompleteness of the entire TMDL plan.

- FA: future allocation
Future allocation refers to the possibility of future modification and development of pollutant characteristics in the pollutant allocation. Like the MOS, it is also similar to the concept of safety factor and is a specific factor preserved during the process of pollutant allocation.

\section{Analysis of limitations in facilitating TQC}

Figure 1 Demonstrates the procedures of TQC implementation and conduction. The current limitations of TQC implementation in Taiwan include lack of background data (such as water quality, water weight, discharge weight and non-point source), immature technologies for simulating water quality (such as experience of model application, as well as the model monitoring system), communication for allowable pollutant allocation for discharge (such as coordination among various authorities and allocation for stakeholders), and relevant laws and measures. To cope with the abovementioned limitations, the EPA plans relevant measures and procedures to facilitate the implementation of the total pollutant quantity control mechanism for waterbodies. As for the details of implementation, it is difficult to conduct the implementation because of incomplete information. First, the calculation of allowable quantity of discharge may provoke some disputes due to the lack of relevant data regarding heavy metal pollution in Taiwan, as well as less application experience of simulating water quality. Moreover, the specific enterprises are only asked to declare the relevant items of heavy metals (for example, Cr for tanning industry) for the regular inspection and the required documents regarding the industrial effluents. Consequently, considering the impact of heavy metals on human health, it is suggested to implement the TQC plan in the basins whose background data are relatively sufficient (for example, Dali River in partial Wu River basin), in priority. As Taiwan applies Water Quality Analysis Simulation Program (WASP) in the simulation of heavy metals and sediments in rivers, the 2D vertical transmission of heavy metals from waterbody to sediments, as well as the calculations on the interaction and relevant suitable parameters, can be included in WASP. As for the basins whose background is relatively sparser, investigating the pollutant sources and applying reduction measures for now to gradually facilitate TQC is suggested. On the other hand, persistent organic pollutants (POPs) have been controlled from the source in accordance with the Toxic Chemical Substances Control Act, Environmental Agents Control Act, and Agro-pesticides Management Act, and the uses of POPs have been banned to prevent the environment and human health from suffering harm. Based on this measure, implementing continuous monitoring and integrating all the relevant results of research conducted by various agencies are suggested so that fundamental data regarding the environmental distribution of organic toxic 


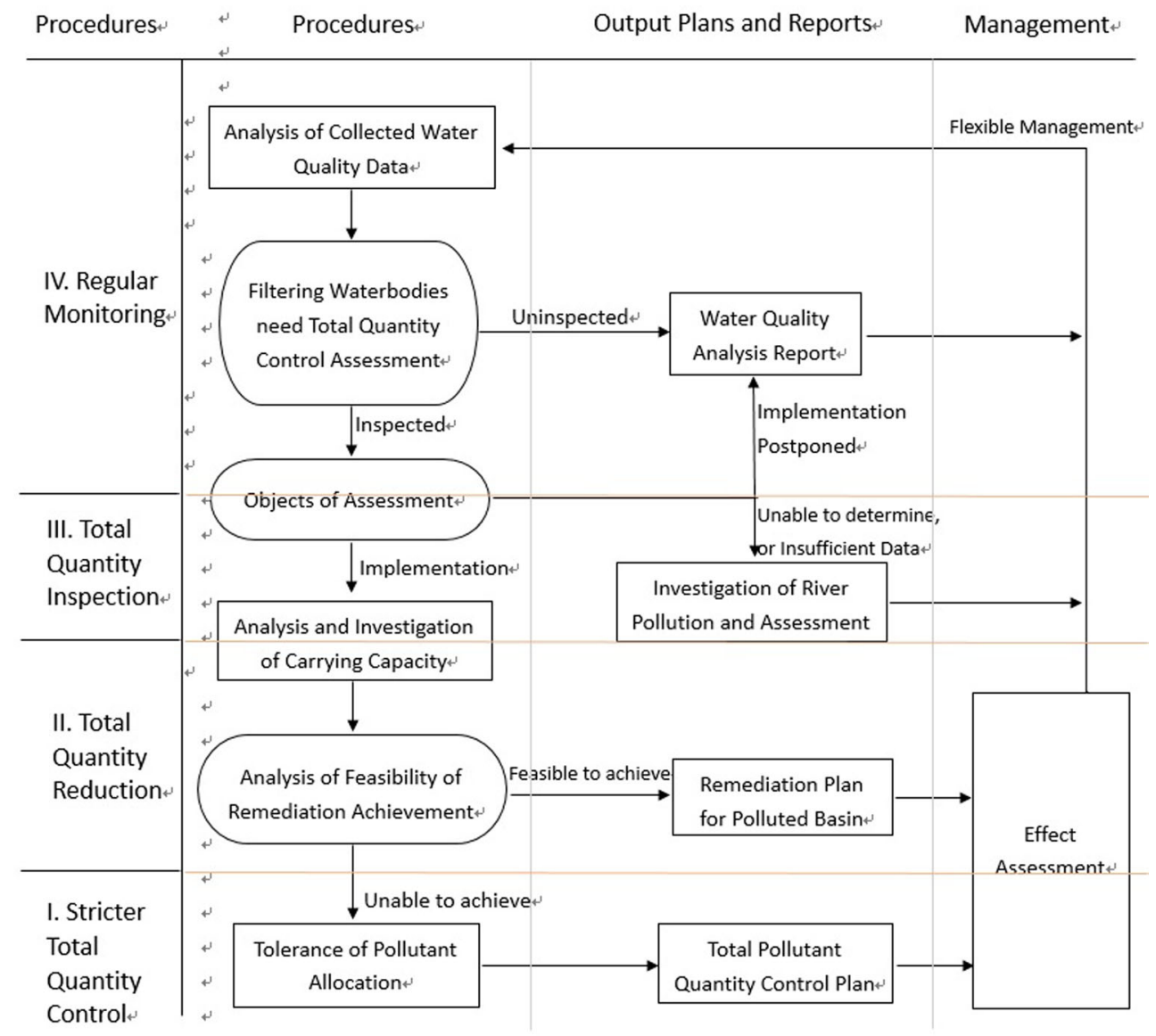

Fig. 1 Procedures of TQC implementation and conduction

chemical substances can be established continuously. By doing so, the POPs hazard assessments and preventive measures can be further facilitated according to the fundamental data. For the implementation to satisfy the policies, it is suggested that the allowable pollutant quantity be calculated based on mass balance, and the quantity to be controlled should be calculated in the strictest manner in order to reduce environmental hazards.

The division of duties and authorities among the executive agencies is presented in Fig. 2. It is suggested that the local authorities draft relevant plans or reports (for example, the TQC Plan, Basin Pollution Remediation Plan, Assessment Plan of River Pollution Investigation, Water Quality Analysis Report, etc.) and submit them to the central authorities according to the contents and procedures of TQC implementation in the jurisdictional basins; the central authorities should consult with relevant target industry competent authorities for ratification to implement. As for the inter-jurisdictional basin between different municipalities, cities, or counties or the specific areas governed by the central target industry competent authorities, the total quantity inspection shall be conducted by local authorities before the EPA consults with local authorities or relevant target industry competent authorities to allocate total pollutant quantities for discharge, and the relevant plans and reports should be drafted by the local authorities.

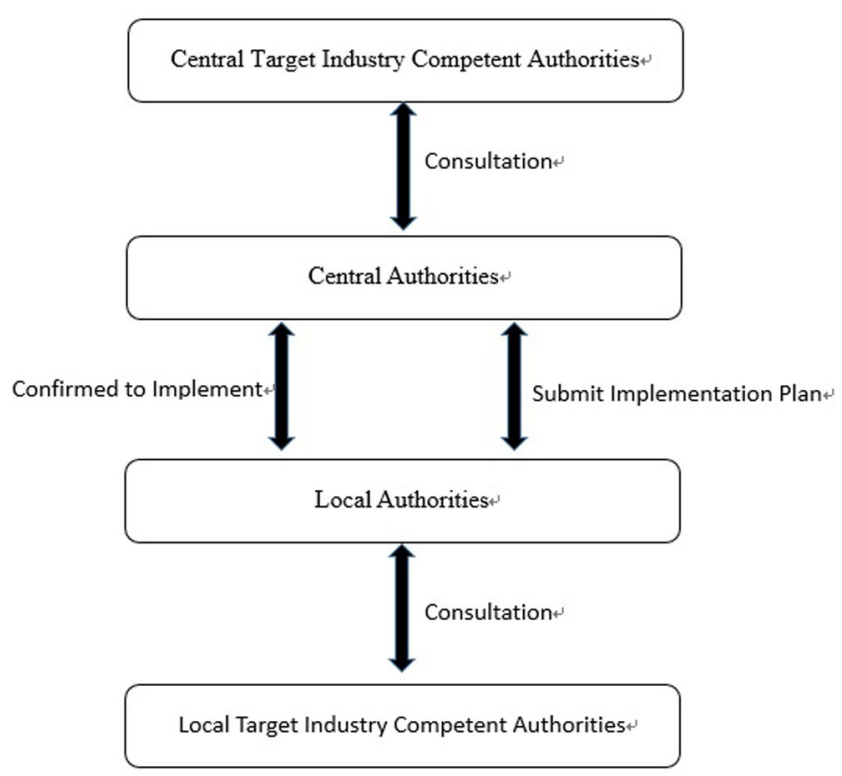

Fig. 2 The division of duties and authorities 


\section{Conclusion}

Drafting a TQC plan involves rather complicated procedures, including dealing with the current legal sources, investigating the hydrographic background and ecology, and verifying the integrity of water quality and pollution data. The authorities can only start planning the TQC after years of collecting and organizing the relevant data and establishing a database. By researching the TQC, the authorities can identify the areas, objects, and quantities of pollutant to be reduced in different stages in advance, after setting targets of water quality in different stages and finishing the simulation calculation. By doing so, the authorities can control the objectives and potential range of impacts ahead of time. Consequently, while the TQC is a feasible measure to manage river basins, it requires other supporting measures, suggested as follows:

The relevant data regarding basins, agriculture and livestock areas, urban areas, and meteorology shall be collected step by step so that the simulation and management of TQC in non-point source pollutions can be conducted more precisely.

An ecological database shall be established, and the carrying capacities of living beings in relation to the pollutants shall be included in the database, so that the database can serve as a benchmark for ecological protection.

The uses of river water shall be investigated thoroughly so that the results can provide a basis for setting targets of water quality management.

The future soil uses shall be considered when calculating total pollutant quantity.

The implementation of TQC plan can be difficult if it is conducted by regarding the organic compounds and nutrient salts as the target compounds since they are the the items consumed in pollutant mass balance analysis. The mass balance equation consists of Control Weight, Inflow, Outflow, Accumulation, and Consumed Item. If heavy metals can be regarded as the target compounds, then the calculation can be easier by simply considering the inflow and outflow since the heavy metals cannot be consumed.

When the soil is regarded as the final receptor (i.e., the accumulation in mass balance equation) of heavy metals in regard to the domestic environmental impact, the atmospheric deposition can be excluded from the major pollutant sources, which are discharged waste water (sewage) and slightly inappropriate disposal of wastes. The relevant laws thus include the Water Pollution Control Act, Trash Clearance Act, and Soil and Groundwater Pollution Remediation Act.

To establish a feasible action plan, it is suggested to identify the heavy metal mass inflow according to the effluent standards of pollutant sources and the discharge permission system, and then to calculate the soil pollution control standards and the investigated polluted farmland areas to identify other sources in the mass balance equation so that the implementation can be conducted through administrative measures in accordance with the results.

For the initial stage of the implementation, the domestic cities and counties where the farmlands are severely polluted, including Taoyuan City, Taichung County, and Changhua County, can be selected as the model areas for the TQC on heavy metals. Since the work is huge and complicated, it requires a large amount of investigation and funding to establish the fundamental database, which can serve as a reference for the policy statement regarding the implementation of future laws and regulations. The executive agencies of the plan in the Administration include the Department of Water Quality Protection and the Soil and Groundwater Remediation Fund Management Board, so it is necessary to establish a cross-department master plan.

To achieve the EPA's prospect of the Green, Clean, and Unpolluted Environment, it is necessary to implement the TQC plan in an administrative manner. The achievement of the prospect requires the collaboration of enterprises, consultant institutions, academic institutions, and government agencies. The process may be difficult, but the outcome will be wonderful. 